\title{
42. Pushing the Boundaries of Your PhD: Exploring Careers Outside the Ivory Tower
}

\author{
Danielle Gilbert ${ }^{1 *}$, S.R. Gubitz ${ }^{2}$, Jennifer Kavanagh ${ }^{3}$, Kelly Piazza ${ }^{1 *}$ \\ 1. United States Air Force Academy 2. Kent Denver School 3. RAND Corporation
}

\section{What Do You Need to Know?}

Discussions about post-graduation career options for political science PhDs typically center around traditional tenure-track positions at large research universities and smaller liberal arts colleges. (See chapters 37, 38, 39, 40 and 41 for insights about working at different types of academic institutions.) However, these narrow discussions ignore the myriad challenging, fulfilling, and intellectually stimulating jobs beyond the ivory tower that are open to political science PhDs. In this chapter, we outline the reasons you might consider a "non-traditional" job, what some of those opportunities look like, and how you can best prepare to secure such a job.

\section{Why Does It Matter?}

There are several reasons why you might want to learn about career opportunities outside the ivory tower.

First, there are many non-traditional academic jobs that require doctoral degrees and are well-paying, policy-relevant, and service-oriented—from fellowships at think tanks to data science positions supporting diverse organizations. Given their own career trajectories, $\mathrm{PhD}$ advisors are often unfamiliar with the diversity of options available and so are unlikely to encourage those studying under them to consider or pursue these options. Plenty of people 
pursue a $\mathrm{PhD}$ without any intention of seeking a traditional academic job and, instead, work toward non-academic careers, challenging the notion that $\mathrm{PhD}$ programs are strictly "vocational schools" for tenure-track faculty positions.

Second, life circumstances and family obligations might dictate that you limit your job search geographically, and these constraints are often incompatible with the flexibility the academic job market requires. Considering non-traditional careers can open new doors and allow you to more effectively balance the work and non-work parts of your life. (Additional strategies for balancing these types of decisions are addressed in chapters 15 on parenthood and 50 on dual hires).

Third, and perhaps most obvious: academic jobs are scarce. Many PhD students have to consider alternative career tracks, even if they had originally hoped to land a traditional academic job. Over the past several decades, the National Science Foundation has repeatedly found that only a minority of $\mathrm{PhD}$-holders are employed in tenure-track positions (McGrath and Davis 2019); a steadily decreasing minority of political science graduates secure a tenure-track position upon graduation (Opsomer et al. 2021). In such a difficult market, it is prudent that graduate students (and their advisors) consider other paths.

Thankfully, there are a wide range of alternative, exciting careers that will use and appreciate your training and expertise. Far from being "lesser" career options, many of these jobs remove the constraints that come with pursuing a tenure-track academic job, allowing you to live where you would like, make more money, influence policy, and give back to your country or community. If any of this sounds appealing, a job outside the ivory tower may be right for you. 
While research, and sometimes teaching, are emphasized as important aspects of political science $\mathrm{PhD}$ programs, graduate school provides an opportunity to master a set of skills that make graduates appealing for "non-traditional" jobs. For example, you know how to:

-Absorb and synthesize information quickly;

-Evaluate competing arguments and identify logical flaws;

-Conduct research, including a mastery of methodological skills;

-Communicate information to a less educated audience;

-Manage long, complicated projects;

-Ask big questions; and

-Interpret important, real-world political phenomena.

All of these skills make you an attractive candidate for a wide range of alternative careers. (See chapter 52 on imposter syndrome if you need further encouragement.) Jobs in professional military educational institutions or pre-collegiate education are a great fit for graduates who love teaching. Policy-oriented positions, including government, think tank, and military institutions, are an excellent fit for graduates interested in policy engagement. PhDs who love co-authoring or working as part of a team will excel in policy-oriented or private sector jobs.

In what follows, we outline four categories of relevant jobs outside the ivory tower, from our own expertise: professional military educational institutions, pre-collegiate education, policy-oriented positions, and private sector jobs. For each, we outline the nature of the career; what characterizes the type of work, daily rhythm, and requirements for work; and relevant pros and cons. Then, we outline how graduate students in political science can become strong 
candidates for these jobs. Last, we offer details about the different application processes for each of these categories.

\section{Academic Jobs “Off The Beaten Path": Professional Military Education}

\section{The Basics: Working at a Professional Military Education Institution}

Aside from traditional colleges and universities, professional military education (PME) institutions employ academics in wide-ranging disciplines to perform teaching, research, and service functions. While similar to traditional colleges and universities in many ways, PME institutions are unique in that they provide professional training, development, and education distinctly to military personnel. There are several categories of PME institutions in the United States: Service Academies, Senior Military Colleges, and Postgraduate Service Schools. The Service Academies, including the U.S. Air Force Academy, U.S. Coast Guard Academy, U.S. Naval Academy, U.S. Merchant Marine Academy, and the U.S. Military Academy at West Point, are exclusively undergraduate institutions that train future military officers . The Senior Military Colleges similarly prepare undergraduates for military service albeit with Reserve Officers' Training Corps (ROTC) programs and corps of cadets that, together, create demanding military environments similar to those at the Academies (Today's Military 2022). Postgraduate Service Schools provide postgraduate education and training to officers in preparation for operational, command, and staff positions and encompass Service Schools, Staff Colleges, Senior Service Colleges, Joint Colleges, and Specialist Training Schools. These institutions are affiliated with one or more branches of the armed forces and include the Command General Staff College, the Air War College, and the Naval Postgraduate School, to name a few. 
PME jobs are great options for political science PhDs committed to teaching, service, and policy relevance. At a military institution, you can expect to teach a heavy load with exceptionally bright, committed students and to carry a comparatively large service load that involves advising, scheduling, and participation in committees. At these institutions, traditional academic research prestige is less important than policy engagement, relevance, and impact. Note that at PME institutions, political science $\mathrm{PhDs}$ might also find jobs in interdisciplinary departments called "National Security Affairs," "Social Sciences," or "Military \& Strategic Studies," to name a few.

\section{Advantages and Disadvantages}

Employment at professional military education institutions has both disadvantages and advantages as compared to more conventional civilian colleges and universities to which graduate students are exposed. Based on our experience as academics trained at prestigious civilian universities and currently employed at a nationally renowned service Academy, we outline those advantages and disadvantages here.

\section{Advantages}

- For political scientists specializing in topics related to national and international security, American foreign policy, grand strategy, and strategic competition, professional military education institutions are extremely well connected, and opportunities to network with subject matter experts abound. 
- The specific mission of PME institutions lead them to be very student-oriented and to prioritize faculty-student interactions. The students are committed and bright and teaching them can be extremely rewarding.

- Faculty positions offer highly competitive salaries and benefits packages, rivaling only the most prestigious academic institutions. Some institutions, like the Air Force Academy (Colorado Springs, CO), the Naval Academy (Annapolis, MD), and the Naval Postgraduate School (Monterrey, CA) are in exceptionally desirable locations.

- Job stability is extremely high at PME institutions, providing faculty with opportunities to pursue their passions, embark on new academic projects, and focus on other personal goals.

- The intimate connection between political science course content and the job responsibilities of military personnel makes it easy to frame relevance of course content and to motivate students.

- For those who are interested, faculty at PME are encouraged to engage with policymakers and the public and are supported in their efforts.

\section{Disadvantages}

- While some disciplines at PME institutions receive substantial funding for research purposes, political science departments are often not as fortunate (unless, of course, research is closely connected to subjects of particular interest to the military). In addition, academics at PME institutions should not expect assistance from teaching or research assistants. Outside of class time, students who might fulfill these functions are preoccupied with military, athletic, and other obligations. 
- As an employee of the U.S. Government, you might face restrictions on where and how you conduct your research. For example, in addition to pursuing research approvals through Institutional Review Boards, some human subjects research has to be approved by other government agencies, presenting hurdles to your work.

- Faculty at PME institutions should expect to have their writing approved through a Public Affairs office before publication.

- PME institutions often have robust core curricula which may translate into more oversight of teaching.

- As PME institutions prioritize accessibility to students, there may be significantly less flexibility in work locations and schedules.

- Government employees are required to complete a substantial number of administrative tasks, and this work takes time away from both teaching and research.

- The military mission may take precedence over academics.

\section{How Should You Prepare?}

You might prepare for a career in PME in much the same way you would prepare for a job at a civilian college or university with some added emphasis on policy-relevant research and of your familiarity with the distinct features of PME institutions. In your pursuit of these positions, you should keep in mind that: 1) PME institutions are typically primarily teaching institutions and interviews often include a teaching demonstration, much as a liberal arts college would; 2) policy engagement, policy-relevant research, and writing for public-facing outlets are desirable and can 
make you an attractive candidate; and 3) service and administrative tasks are non-negotiable and enthusiasm about these duties may help to set you apart from other candidates.

\section{Pre-Collegiate Education}

\section{The Basics: Working in Pre-Collegiate Education}

Many $\mathrm{PhD}$ programs and post-PhD careers place a heavy emphasis on research and somewhat less emphasis on the teaching component of the job. So, what is a PhD candidate to do when they are passionate about teaching and find themselves interrupted by research expectations, rather than the other way around?

Of course, there are several career paths for an aspiring educator in the academy. Small Liberal Arts Colleges (SLACs) offer some of the most rigorous education in the United States, and professors at these schools experience a lower threshold for research output (and fewer resources) than their colleagues at the large top tier research universities (or R1s). Community colleges can be found in nearly every mid-sized city in America, and one will be hard pressed to find more dedicated educators than the professors at these institutions. But positions in SLACs are perhaps even harder to come by than tenure-track positions at R1 universities. And while community college positions can be professionally rewarding, their relatively meager compensation packages can often dissuade those with serious financial considerations or familial responsibilities from applying. However, precollegiate education at independent schools can present the perfect opportunity for the right $\mathrm{PhD}$ candidate who is interested primarily in education as their end goal. 
Independent schools, sometimes also called "private schools" run the gamut from religious schools to secular day and boarding schools. The U.S. Department of Education reports that there are over 30,000 independent schools in the country (compared to the nearly 100,000 public schools the Department tracks). Compared to the 4,000 institutions of higher education in the country, independent schools present a more plentiful, diverse, and readily available job market than in academia. But how does a PhD in Political Science translate to teaching high school students? ${ }^{1}$

First and foremost, it is important to understand what being an independent schoolteacher is and is not. If you fantasize about being an educator at a secondary school because you believe it will somehow give you more time to pursue research independent of any overbearing institution, you may want to look elsewhere. Being an independent school teacher means being an educator of children through and through; your job description begins and ends at teaching. You will be spending most of your time either grading, making lesson plans, sponsoring a student club, coaching a sport, or even talking to a concerned (or happy!) parents. If the thought of these things excites you, then you are the right sort of person for these positions. If not, then you may want to peruse the other sections of this chapter. Although it is possible to spend a year or two as an independent school teacher and then return to academia, the bottom line is that if you are interested in pursuing this career path long-term, your career in research is likely over.

\section{Advantages and Disadvantages}

\footnotetext{
${ }^{1}$ This section focuses on high school education but could apply as well to middle or primary school.
} 
Compared to positions in collegiate education, positions in independent schools come with many differences, both advantages and disadvantages. We outline some of those here.

- As noted above, you will be educating children. Teaching children comes with its own unique challenges and rewards. To be blunt, educating a child is more about emotional and behavioral support than it is about the content you are probably used to emphasizing. While this may entail a host of responsibilities, it also means fostering incredible relationships with your students. As a teacher at an independent school, you are more than just their teacher. Indeed, schools have in loco parentis when parents drop their children off at school. In addition, you can help set the foundation on which your students will build their education.

- Unlike the traditional academic job market, the market for jobs at independent schools is typically excellent. These positions come with excellent compensation, and compensation packages are incredibly negotiable. You will likely receive more interviews than you know what to do with and likely be presented with multiple offers. While many independent schools follow a pay scale based on experience, the definition of "experience" is itself negotiable. And the best part is that this negotiation is not only expected - it is encouraged to help with retention.

- These jobs feature enticing benefits. Most schools offer matching contributions to retirement accounts, whether they are traditional $401 \mathrm{k}$ or TIAA programs. Additionally, these schools typically offer competitive health insurance policies, family leave policies, and even daycare programs in some cases. Finally, many independent schools offer their education to children of faculty for steeply discounted rates. 
There has been much recent discussion about the equity of independent schools, with many arguing that they foster elite, privileged attitudes and worsen existing inequities. If you are interested in pre-collegiate education but share these concerns, there are a few things worth keeping in mind. First, independent schools often have generous need-based financial aid offerings for students who cannot afford the full tuition; indeed, some schools provide some form of aid to anywhere between a quarter to a third of their students. This means that these schools can diversify their student body. And while there is always room for improvement in this area, many are actively working toward this goal. School efforts in these areas are typically readily apparent and you can use this information to shape your search for employment. Independent schools are also smaller and more flexible than universities and opportunities abound for you to advocate for changes that you value. Furthermore, the children at these schools, regardless of their background, are often passionate about issues of diversity, equity, and inclusion and may be willing partners in efforts towards change.

\section{How Should You Prepare?}

Translating your PhD in Political Science to teaching at an independent school is probably easier than you think. Most high schools do not offer courses in "political science," per se. Instead, you will likely be applying for positions in social studies, history, social science, or civics programs. These are broad categories that cover everything from world history to U.S. history to courses on economics and philosophy. That means that you need to translate that very specific thing you have been studying for years into this broad category; essentially, lead with 
your primary field and talk about your dissertation only when you are asked directly about it. Regarding your qualifications, these schools care about two things: (1) that you have the pedagogical skills to teach anything in their course offerings; and (2) that you have completed a $\mathrm{PhD}$. When these schools hire $\mathrm{PhD}$ candidates, they understand that they are hiring a subject matter expert who can learn on the job and, most important, teach well.

The actual application process will look very different from that for jobs at R1s or SLACs and the materials you will need to submit will also be very different. If you pursue this career option, you will likely want to find a recruitment agency like Carney Sandoe and Associates or one of their competitors to help you navigate this job market. These firms help qualified candidates find employment in the wide-ranging independent school market and make money only when you accept a position somewhere (i.e., the school pays them a finder's fee or a subscription fee to access their candidate pool). Firms like these can help you tailor your application materials to this unfamiliar market; you can be assured that you are not their first $\mathrm{PhD}$ candidate.

\section{Public Policy-Focused Opportunities}

\section{The Basics: Working in Public Policy-Focused Organizations}

In addition to teaching jobs, there are also many opportunities for those with a political science $\mathrm{PhD}$ in the policy world. While pre-collegiate education allows candidates to focus on teaching almost exclusively, policy-oriented positions emphasize research and application. Research organizations and think tanks, advocacy organizations, non-profits, and federal and state governments are all looking for job applicants with the analytical and methodological skills as 
well as the substantive knowledge that political science $\mathrm{PhD}$ programs provide. Jobs in the policy-field are diverse and have varying requirements and demands. In this section we provide a broad description of some common jobs in this field, as well as advantages and disadvantages of policy-related careers compared to the traditional academic track. We also discuss things to keep in mind and pursue as you complete your degree that can help prepare you for a career in the policy world.

Although diverse, policy-related jobs tend to have some common characteristics.

- Most involve some sort of research and analysis responsibilities along with writing and publishing reports. There are also typically meetings with clients, seminars, data collection trips, as well as other activities and responsibilities.

- All are focused on using this research and analysis to inform, evaluate, shape, implement, or improve public policy. In many cases, the actual topics, questions, and research methods employed in the policy domain are not all that different from those in academia. However, the emphasis is always on identifying the policy implications or recommendations that derive from the research. This is not to say that work coming out of academia never informs policy. However, for policy-oriented jobs, the policy questions and needs are the driving focus of the research and in fact may shape the research questions and agendas themselves.

- Much of the work done at policy-oriented organizations and within the government involves working with interdisciplinary teams. While co-authoring and collaborating are not uncommon in academia, working in multidisciplinary teams is the widespread norm in policy work. In part, this is because the questions tackled by policy-oriented work are often broad 
and so require multiple lenses and larger teams. However, it is also just a different approach to tackling hard questions, geared more around a consultancy model.

- Most allow opportunities for other activities, like teaching as an adjunct at nearby universities. This can be a great way to continue teaching without pursuing a tenure track position or committing to a full-time teaching job.

Apart from these similarities, however, the type of work that you will do in the policy world will depend on the organization that hires you. Most obviously, the topics you work on will be determined by the focus of the think tank or organization. For example, there are research organizations focused solely on social and economic policy like the Urban Institute, those that focus largely on international and security-related work like the Center for Strategic and International Studies, and those that do both like the RAND Corporation. Similarly, there are NGOs focused on everything from international development to arms control to education. And of course, government agencies focus on diverse issues across sectors. If you are considering a policy-oriented career, the first step would be to determine the type of work that you want to do and then to identify the agencies and organizations that focus on the issues you are interested in.

\section{Advantages and Disadvantages}

Policy-oriented jobs come with a range of differences, challenges, and opportunities when compared to traditional academic jobs and even to each other.

- The amount of control over research agendas varies across organizations. If you are considering a policy or research career, you should determine how much flexibility you need, how much fundraising you want to do, and how much you are willing to have your 
research agenda set by external events, as this may influence the types of organizations you choose to target. Some organizations rely on grants and donations, which means that researchers will need to compete for Request for Proposals (RFPs) and be able to bring in money to support their research. Other organizations, including Federally Funded Research and Development Centers, have longer term government contracts. While these contracts provide more consistent funding, they also determine the client base and sometimes shape the research agenda. ${ }^{2}$ Research within government agencies is obviously government-funded with the research agenda being set by priority policy issues and senior leaders within those agencies.

- Opportunities for external publication may be more limited and will almost certainly be of a different style than you are used to from your graduate career. You should consider how important it is for you to publish externally. While some organizations encourage their employees to publish commentaries and articles, at other organizations, especially those associated with the national security establishment, opportunities for external publishing are more limited and require special approvals. It is still possible to achieve a far-reaching impact, however, with unpublished work.

- The style of policy publications may be very different from academic journals and it may vary from organization to organization. This writing style is something you will likely learn on-the-job, but it is worth becoming familiar with how different organizations frame their research and the types of products they publish since knowing both may inform how you present yourself in a cover letter or at a job interview.

\footnotetext{
${ }^{2}$ Federally Funded Research and Development Centers "are owned by the federal government, but operated by contractors, including universities, other nonprofit organizations, and industrial firms." See Congressional Research Service, 2020.
} 
- Organizations and positions vary in their relationship to politics and political parties. While some organizations are explicitly non-partisan, others have clear and known political affiliations or leanings that may be worth considering in the application process.

- There may be variation in the amount of research and writing compared to more direct policy-oriented staff work or advising that is involved. Working in a think tank or research organization is likely to involve writing longer, research-intensive reports and commentaries, whereas jobs in government may include writing policy memorandums or preparing briefings For those working in government, there is also likely to be some amount of administrative or "staff work" which may be less stimulating, but is required to keep the organization functioning and to respond to near-term and emerging demands.

- Compensation in policy-oriented jobs tends to be as high or higher than that of most comparable tenure track positions at R1s or SLACs, although there is variation across organizations. Many also offer flexibility in work style and location. While many policy jobs are Washington D.C.-based, there are policy-focused, advocacy, and non-governmental organizations in most major cities across the country and globe, and many organizations have multiple offices or flexibility for remote work. The one exception to such flexibility pertains to jobs in the national security sector which may require a security clearance and involve primarily in-person work in secure facilities (more on this below).

\section{How Should You Prepare?}


Preparing to pursue policy-related opportunities after graduate school does not require a radical departure from the path to academic jobs. However, there may be some things worth keeping in mind as you continue your graduate career that can help you be a successful candidate and ultimately successful in your chosen job.

- It can be helpful to take some policy-oriented coursework or seek out policy-oriented opportunities on campus while you are a student. Organizations that hire political science $\mathrm{PhDs}$ do consider familiarity with the policy world when identifying promising applicants and will ask you to speak about policy issues, so having some experience can be helpful.

- Methods courses are highly useful in this field. Since the work you do at policy-oriented research organizations may vary as policy issues and priorities shift, having a strong methodological toolkit that you can apply to myriad questions and topics can make you an appealing candidate.

- Get used to framing your research projects around policy implications and ensure that your dissertation and/or job talk has a section on policy implications. It is easy to tell when policy implications have been appended at the last minute. Policy implications must be central to the project if they are to appear organic and lead to well-supported recommendations.

- There are a number of summer, semester, and pre/post doctoral programs that you can use to prepare yourself for policy-oriented positions.

o Training Programs: The Bridging the Gap (BtG) Project's New Era Workshop (Bridging the Gap, undated), International Policy Scholars Consortium and Network (IPSCON) (Henry A. Kissinger Center for Global Affairs, undated), and the Clements Center's Summer Seminar in History and Statecraft (The University of Texas at Austin, 
undated) all provide extra-curricular training opportunities for graduate students interested in pursuing policy careers. These programs, ranging from three days $(\mathrm{BtG})$ to a year-long program (IPSCON) are a fantastic way to network with like-minded junior and senior scholars while honing policy-relevant skills.

o Summer or Term Internships: Many research organizations hire PhDs for paid summer internships that provide an opportunity to explore policy-related research for a period of time. These programs can be a great way to gain insight into what it is like to work in the policy world. Organizations with such programs often use them to identify potential permanent hires. Examples include the RAND Corporation's Graduate Student Summer Associate program (RAND Corporation, undated) or CNA's Research Student Summer Internship Program (CNA, undated).

- Many think tanks and research organizations now have virtual connections for many of their events. Consider signing up to receive alerts about upcoming seminars at one or more organizations so that you can get a better sense of the issues discussed and the way questions and research findings are framed.

- Spend time looking at the websites and publications of organizations where you think you might be interested in working. You will want to understand their research and writing style, what types of evidence and arguments they tend to use, and what types of graphics they tend to employ. These things can help you think about how you might communicate your research portfolio, skills, and strengths if you decide to apply. 
- Talk to people who work at organizations where you think you might like to work by reaching out to them directly or using conferences, whether virtual or in-person, as a meeting opportunity.

- Policy jobs on the national security-side typically require a security clearance. This will be almost universally true of government jobs, but may not always be true in the non-profit or advocacy space. Security clearance eligibility requires U.S. citizenship along with a range of other factors. If you think you might apply to a job that requires a security clearance, it is a good idea to review the requirements and process (see for example, Indeed Editorial Team, 2021).

\section{Private Sector Jobs}

In addition to the opportunities discussed already, political science $\mathrm{PhDs}$ also have numerous opportunities at private sector companies serving in a range of capacities. Private companies like McKinsey, Boston Consulting Group, Amazon, Facebook, Google, Microsoft, and others often hire individuals with a political science $\mathrm{PhD}$ to support their consulting and other work with government clients, to conduct geopolitical risk assessments, to support the research arm of their organization (for example, Facebook employs PhDs to study their platform and to develop strategies for countering extremism), or to work in strategic planning. These organizations seek out political science PhDs for their methodological training, their systematic way of approaching complex questions, and also in many cases for their regional or substantive expertise. These companies offer exciting and well-compensated opportunities and can be found nationwide. These jobs and the optimal ways to prepare to apply for them are too diverse to 
adequately characterize here, but if you are interested in pursuing this path, you should feel confident in doing so with your PhD qualifications. To prepare and learn more, consider looking at company websites and seeking out contacts who might work at these places.

\section{Conclusion}

This chapter has described a range of non-traditional opportunities for political science $\mathrm{PhD}$ candidates and graduates to consider as they chart their careers. Although moving into one of the career paths described here is becoming increasingly common, limited information about these options is conveyed to students in $\mathrm{PhD}$ programs at major universities. This chapter provides resources for students to fill this gap. A key theme across the chapter is that your political science $\mathrm{PhD}$ makes you a highly sought after candidate in a range of fields and offers you many paths to fulfillment and success, both in your career and outside of it. It is worth exploring these opportunities even if you think working at an R1 is what you want—you may be surprised what you find!

*DISCLAIMER: The views expressed in this article, book, or presentation are those of the author and do not necessarily reflect the official policy or position of the United States Air Force Academy, the Air Force, the Department of Defense, or the U.S. Government. PA\#: USAFA-DF-2022-13

\section{References}

Bridging the Gap. Undated. New Era Workshop, https://bridgingthegapproject.org/programs/new-era/.

CNA. Undated. Research Student Summer Internship, https://www.cna.org/careers/internship Congressional Research Service. 2020. "Federally Funded Research and Development Centers (FFRDCs): Background and Issues for Congress." https://crsreports.congress.gov/product/pdf/R/R44629/6

Henry A. Kissinger Center for Global Affairs. Undated. International Policy and Scholars Consortium and Network, https://sais.jhu.edu/kissinger/ipscon 
Indeed Editorial Team. 2021. "How to Get a Security Clearance."

https://www.indeed.com/career-advice/career-development/how-to-get-security-clearance

McGrath, Erin and Megan Davis. 2019. "APSA Graduate Placement Report: Analysis of Political Science Placements for 2017-2018." Political Science Education and the Profession. July. https://preprints.apsanet.org/engage/apsa/article-details/5d2dd689f4cf65001aa0744b.

Opsomer, Jean, Angela Chen, Wan-Ying Chang, and Daniel Foley. 2021. "U.S. Unemployment Higher in the Private Sector than in the Education Sector for U.S.-Trained Doctoral Scientists and Engineers: Findings from the 2019 Survey of Doctorate Recipients." National Center for Science and Engineering Statistics. April. https://ncses.nsf.gov/pubs/nsf21319.

RAND Corporation. Undated. Graduate Student Summer Associate Program, https://www.rand.org/about/edu_op/fellowships/gsap.ht

The University of Texas at Austin. Undated. Clements Center for National Security, Summer Seminar in History and Statecraft, https://www.clementscenter.org/programs/clements-summer-seminar-in-history-and-state craft

Today's Military. 2022. "Education \& Training: Military Schools." https://www.todaysmilitary.com/education-training/military-schools?gclid=Cj0KCQiA2Z COBhDiARIsAMRfv9IQbjvkU-i-DlpoZb3p4t-XSmE3Ci04yQsa_j3T7dFOM2LfqoVllU kaArdOEALw wcB\&gclsrc=aw.ds 